\title{
Reduced mean platelet volume levels predict shorter survival in patients with resectable pancreatic ductal adenocarcinoma and type 2 diabetes
}

Ji-bin Yin ${ }^{1 *}, \mathrm{Na} \mathrm{Li}{ }^{2}$, Ming-ming Cui ${ }^{2}$, Xin Wang ${ }^{2}$ and Rui-tao Wang ${ }^{2^{*}}$

\begin{abstract}
Background: Type 2 diabetes mellitus (T2DM) increased the risk of developing pancreatic cancer. Pancreatic ductal adenocarcinoma (PDAC) is the most common neoplastic disease originating from the pancreas. Increasing evidence indicates that platelets activation plays a prominent role in tumor and T2DM. Mean platelet volume (MPV) is an indicator of activated platelets and is altered in several cancers. The current study aimed to evaluate the prognostic role of MPV in resectable PDAC patients with T2DM.

Methods: Eight hundred and three patients with PDAC were included in this retrospective study. We determined the optimal cutoff value of MPV for 5-year overall survival (OS) using the receiver operating characteristic (ROC) method. The associations between MPV levels and clinical characteristics were analyzed. Kaplan-Meier survival analysis and Cox's proportional hazard regression model were used to evaluate the prognostic value of MPV for OS.

Results: Compared to the PDAC patients without T2DM, MPV levels were significantly higher in the PDAC patients with T2DM. Moreover, MPV was significantly associated with the differentiation between T2DM and non-T2DM. In addition, Kaplan-Meier analysis found that patients with low MPV levels had a poorer 5-year OS than patients with high MPV levels in diabetic patients. Multivariate analyses revealed that MPV was an independent prognostic factor for OS in patients with T2DM. However, the independent prognostic role of MPV was not observed in patients without T2DM.
\end{abstract}

Conclusion: MPV independently predicts poor survival in PDAC patients with T2DM. Prospective studies are required to confirm the role of MPV in PDAC.

Keywords: Pancreatic ductal adenocarcinoma, Type 2 diabetes mellitus, Survival, Mean platelet volume, Prognosis

\footnotetext{
*Correspondence: yjb125@sohu.com; ruitaowang@126.com

'Department of Gastroenterology, The Second Affiliated Hospital of Harbin

Medical University, Harbin Medical University, No. 246 Xuefu ST, Nangang

District, Harbin 150086, Heilongjiang, China

${ }^{2}$ Department of Internal Medicine, Harbin Medical University Cancer Hospital, Harbin Medical University, NO.150 Haping ST, Nangang District, Harbin

150081, Heilongjiang, China
}

C C The Author(s). 2020 Open Access This article is licensed under a Creative Commons Attribution 4.0 International License, which permits use, sharing, adaptation, distribution and reproduction in any medium or format, as long as you give appropriate credit to the original author(s) and the source, provide a link to the Creative Commons licence, and indicate if changes were made. The images or other third party material in this article are included in the article's Creative Commons licence, unless indicated otherwise in a credit line to the material. If material is not included in the article's Creative Commons licence and your intended use is not permitted by statutory regulation or exceeds the permitted use, you will need to obtain permission directly from the copyright holder. To view a copy of this licence, visit http://creativecommons.org/licenses/by/4.0/ The Creative Commons Public Domain Dedication waiver (http://creativecommons.org/publicdomain/zero/1.0/) applies to the data made available in this article, unless otherwise stated in a credit line to the data. 


\section{Background}

Pancreatic ductal adenocarcinoma (PDAC) is the most common type of cancer originating from the pancreas and the fourth leading cause of cancer-related deaths [1]. PDAC has a 5 -year overall survival (OS) of $8 \%$ for all stages combined [2]. The existence of type 2 diabetes mellitus (T2DM) reflects pancreatic dysfunction and facilitates pancreatic tumorigenesis [3]. In addition, T2DM predicts worse survival outcomes in patients undergoing pancreatic resection [4]. Although the progress has been made in therapeutic approaches, however, the survival rate of PADC patients remains low. Therefore, effective molecular targets better predicting survival outcome are urgently needed in PDAC.

Platelets are implicated in tumor biology through the direct interaction with tumor cells [5]. Thrombocytosis correlates with worse overall survival in gastric cancer, pancreatic cancer, colorectal cancer, endometrial cancer, and ovarian cancer [6-10]. However, platelet number is related to production and consumption. Platelet count is normal when pro-inflammatory state and efficient compensatory mechanisms coexisted [11].

Mean platelet volume (MPV) reflects platelet size and indicates platelet activation [12]. Platelet activation acted as an active role in cancer progression and metastasis [13]. Altered MPV levels were observed in several malignancies, such as gastric cancer, ovarian cancer, lung cancer, colorectal cancer, and breast cancer [14-18]. Moreover, MPV is associated with a number of diabetic complications such as diabetic macular edema, microalbuminuria, coronary severity scores, and stroke [19-23]. However, to our knowledge, there has been no report describing its value in PDAC patients with T2DM.

The study aimed to examine the predictive significance of MPV in PDAC patients with T2DM.

\section{Methods}

\section{Study population}

This study consisted of 803 consecutive PDAC patients (median age 60.0 years, range $21-78$ years) in Harbin Medical University Cancer Hospital from January 2010 to December 2013. All patients underwent surgical resection. Patients with the following characteristics were included: 1) age > 21 years; 2) pathologically confirmed PDAC; 3) no distant metastasis; 4) no chemotherapy or radiotherapy before operation. The exclusion criteria were as follows: 1) other malignancies diagnosed within 5 years; 2) acute infection; 3) hematological disorders, 4) treatment with acetylic salicylic acid; and 5) no complete follow-up data. The clinical staging was determined by TNM staging system of the American Joint Commission on Cancer (AJCC) 8th edition. Diabetes mellitus (DM) was defined as a prior diagnosis or fasting serum glucose was $\geq 7.0 \mathrm{mmol} /$ $\mathrm{L}$ or random serum glucose was $\geq 11.1 \mathrm{mmol} / \mathrm{L}$ or based on medication. The time from diagnosis to death or last follow-up was measured as overall survival (OS). Followup was completed on December 31, 2018.

The protocol was approved by the ethical committee review board of Harbin Medical University Cancer Hospital. All patients involved in the study gave written consent for this study.

\section{Statistical analysis}

We used SPSS Statistics version 25.0 (SPSS Inc., Chicago, IL, USA) to analyze data. Continuous variables were

Table 1 The clinicopathological features among PDAC patients in relation to T2DM status

\begin{tabular}{|c|c|c|c|}
\hline Variables & With T2DM & Without T2DM & $P$ value \\
\hline $\mathrm{N}$ & 202 & 601 & \\
\hline Age (years) & $61.7(8.7)$ & $58.2(10.9)$ & $<0.001$ \\
\hline Sex (male, \%) & $120(59.4)$ & $367(61.1)$ & 0.676 \\
\hline $\mathrm{BMI}\left(\mathrm{kg} / \mathrm{m}^{2}\right)$ & $23.4(3.2)$ & $23.1(3.3)$ & 0.183 \\
\hline Smoker (n, \%) & $61(30.2)$ & $206(34.3)$ & 0.287 \\
\hline Drinking (n, \%) & $44(21.8)$ & $113(18.8)$ & 0.356 \\
\hline FPG $(\mathrm{mmol} / \mathrm{L})$ & $8.45(6.70-11.10)$ & $5.40(4.95-6.10)$ & $<0.001$ \\
\hline Albumin (g/L) & $40.4(6.7)$ & $40.1(6.4)$ & 0.599 \\
\hline WBC $\left(\times 10^{9} / \mathrm{L}\right)$ & $7.38(3.19)$ & $6.72(2.77)$ & 0.005 \\
\hline Hemoglobin (g/dl) & $129.0(15.2)$ & $129.9(17.7)$ & 0.512 \\
\hline Platelet count $\left(\times 10^{9} / \mathrm{L}\right)$ & $216.6(87.2)$ & $223.6(78.0)$ & 0.278 \\
\hline MPV (fL) & $9.9(1.9)$ & $10.3(2.0)$ & 0.011 \\
\hline CA19-9 (IU/mL) & & & 0.577 \\
\hline$\leq 37$ & $38(18.8)$ & $124(20.6)$ & \\
\hline$>37$ & $164(81.2)$ & $477(79.4)$ & \\
\hline Tumor location & & & 0.240 \\
\hline Head & $135(66.8)$ & $374(62.2)$ & \\
\hline Body, tail & $67(33.2)$ & $227(37.8)$ & \\
\hline Tumor differentiation & & & 0.092 \\
\hline Well/moderate & $170(84.2)$ & $533(88.7)$ & \\
\hline Poor & $32(15.8)$ & $68(11.3)$ & \\
\hline Tumor size $(\mathrm{cm})$ & & & 0.156 \\
\hline$\leq 4$ & $158(78.2)$ & $497(82.7)$ & \\
\hline$>4$ & $44(21.8)$ & 104 (17.3) & \\
\hline $\begin{array}{l}\text { Regional lymph node } \\
\text { metastasis }\end{array}$ & & & $<0.001$ \\
\hline NO & $124(61.4)$ & $464(77.2)$ & \\
\hline N1 & $69(34.2)$ & 111 (18.5) & \\
\hline N2 & $9(4.5)$ & $26(4.3)$ & \\
\hline $\begin{array}{l}\text { Postoperative adjuvant } \\
\text { chemotherapy }\end{array}$ & & & 0.334 \\
\hline Yes & $103(51.0)$ & $330(54.9)$ & \\
\hline No & $99(49.0)$ & $271(45.1)$ & \\
\hline
\end{tabular}

T2DM type 2 diabetes mellitus; PDAC pancreatic ductal adenocarcinoma; $B M I$ body mass index; FPG fasting plasma glucose; WBC white blood cells; MPV mean platelet volume 
presented as means $\pm \mathrm{SD}$ or medians and compared with the Student's $t$ test or Mann-Whitney $U$ test. Categorical variables were presented as numbers and percentages and compared with the $\chi^{2}$ test. Associations between prognostic factors and OS were estimated by the Kaplan-Meier method and assessed by the log-rank test. Cox's proportional hazard regression model was used to assess the independent predictors for OS. The variables with a $P$-value less than 0.10 in univariate analysis were included in the multivariate Cox analysis. The cut-off value of MPV was determined using receiver-operating characteristics (ROC) curve analysis. A $p$ value of $<0.05$ was considered statistically significant.

\section{Results}

Among the 803 patients, 487 (60.6) were men and 316 (39.4) were women, and the median age was 60.0 years (range 21-89). 202 PDAC patients were categorized as T2DM (median age was 61.5 years), and 601 PDAC patients were categorized as non-T2DM (median age was 59.0 years). The baseline characteristics of the patients are listed in Table 1. Compared with the patients without T2DM, the patients with T2DM were older and had higher WBC and MPV levels. Regional lymph node metastasis were more common in T2DM group. However, tumor location, tumor size, tumor differentiation, and postoperative adjuvant chemotherapy were not significantly different between the groups.

The optimal cut-off value of MPV for OS prediction was $10.0 \mathrm{fL}$ according to the ROC curve with $75.1 \%$ sensitivity and $71.4 \%$ specificity (Fig. 1). Patients were

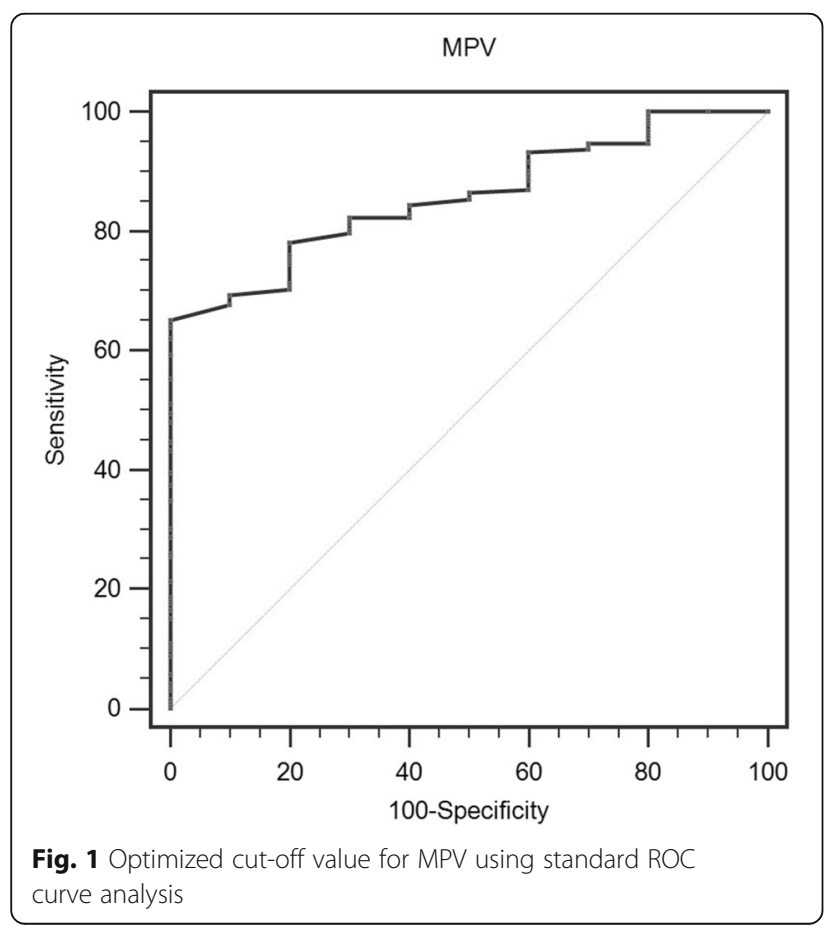

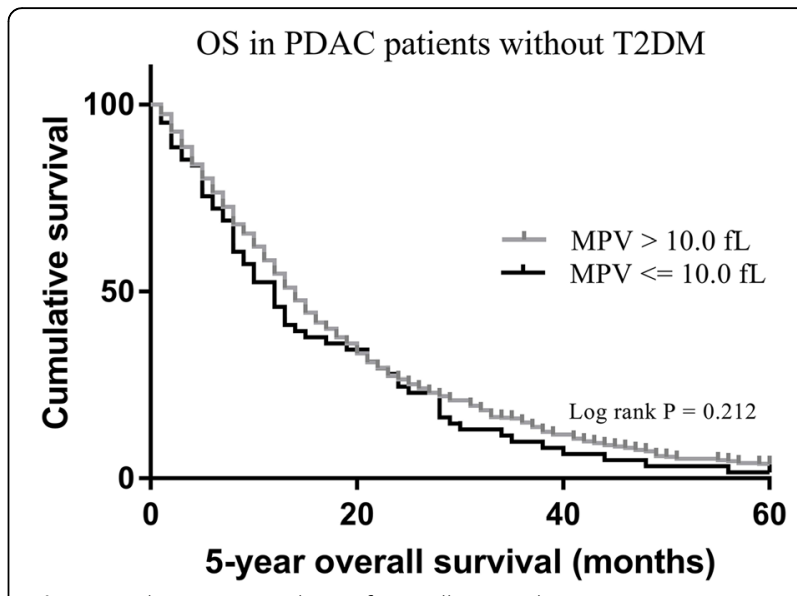

Fig. 2 Kaplan-Meier analysis of overall survival in PDAC patients without T2DM

divided into two groups using this cut-off value. This cut-off value corresponds to an AUC of 0.857 (95\% CI: $0.801-0.902, p<0.001)$.

579 (96.3\%) patients without T2DM had death events with a median follow up of 18.3 months. In this group without T2DM, the 5-year OS of patients according to different MPV levels did not show a significant difference (1.6\% vs. $3.9 \%, p=0.212)$ (Fig. 2). 192 (95.0\%) patients with T2DM had death events with a median follow up of 13.0 months. In this group with T2DM, patients with low MPV levels $(\leq 10.0 \mathrm{fL}$ ) showed significantly shorter OS compared to those with high MPV levels (> $10.0 \mathrm{fL})(0 \%$ vs. $12.7 \%, p<0.001)$ (Fig. 3$)$.

The risk factors for distinguishing T2DM from nonT2DM were evaluated using logistic regression analysis in Table 2. Age, MPV, WBC, and regional lymph node metastasis were significantly associated with differentiation in the regression analysis (for MPV, $\beta=0.904 ; p=0.024$ ).

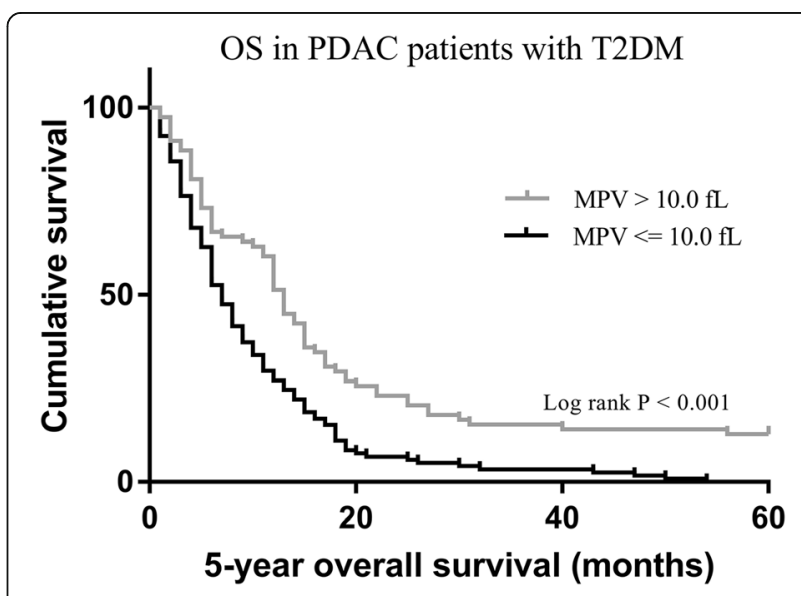

Fig. 3 Kaplan-Meier analysis of overall survival in PDAC patients with T2DM 
Table 2 Logistic regression analysis on baseline variables associated with T2DM

\begin{tabular}{llll}
\hline Variables & $\beta$ & OR $(95 \% \mathrm{Cl})$ & $P$-value \\
\hline Age (years) & 1.033 & $1.016-1.050$ & $<0.001$ \\
WBC $\left(\times 10^{9} / \mathrm{L}\right)$ & 1.073 & $1.017-1.132$ & 0.010 \\
MPV $(\mathrm{fL})$ & 0.904 & $0.829-0.987$ & 0.024
\end{tabular}

Regional lymph node metastasis

\begin{tabular}{llll}
$(\mathrm{N} 1+\mathrm{N} 2$ versus N0) & 2.069 & $1.460-2.932$ & $<0.001$ \\
\hline
\end{tabular}

Abbreviations: see to Table 1

On univariate Cox regression analysis, platelet count, CA19-9, tumor location, tumor size, tumor differentiation, regional lymph node metastasis, and postoperative adjuvant chemotherapy were significantly correlated with OS in patients with non-T2DM (Table 3). Gender, WBC, MPV, CA19-9, tumor size, tumor differentiation, regional lymph node metastasis, and postoperative adjuvant chemotherapy were significantly correlated with OS in patients with T2DM (Table 4).

In multivariate analysis, CA19-9, tumor differentiation, regional lymph node metastasis, and postoperative adjuvant chemotherapy were independently associated with
OS in patients with non-T2DM (Table 3). MPV, CA19-9, and postoperative adjuvant chemotherapy were independently associated with OS in patients with T2DM (Table 4).

\section{Discussion}

Our study revealed three important clinical findings. First, patients with T2DM had higher MPV levels than those in patients without T2DM. Second, MPV was significantly associated with differentiation between T2DM from non-T2DM. Third, MPV is an independent prognostic factor for OS in PDAC patients with T2DM.

The relationship between pancreatic cancer and diabetes is complex because causal relationship between the two is not clear. T2DM is associated with an increased risk for PDAC [24]. Hyperinsulinemia reduces the production of insulin-like growth factor (IGF) binding protein and results in the increase of bioavailable IGF-1 [25]. IGF-1 receptor binding activates PI3K/Akt and Raf/MAPK pathways, which further stimulate the growth of pancreatic cancer cells and inhibits apoptosis [26]. On the other hand, IGF-1 promotes tumor cell invasion and inhibits tumor suppressor phosphatase and tensin homolog (PTEN) [27]. In addition, advanced

Table 3 Univariate and multivariate analysis of overall survival in PDAC patients without T2DM

\begin{tabular}{|c|c|c|c|c|}
\hline \multirow[t]{2}{*}{ Variables } & \multicolumn{2}{|l|}{ Univariate analysis } & \multicolumn{2}{|l|}{ Multivariate analysis } \\
\hline & $\mathrm{HR}(95 \% \mathrm{Cl})$ & $P$-value & $\mathrm{HR}(95 \% \mathrm{Cl})$ & $P$-value \\
\hline Age (years) (> 60 versus $\leq 60)$ & $1.139(0.967-1.343)$ & 0.120 & & \\
\hline Gender (Male versus Female) & $1.022(0.864-1.207)$ & 0.802 & & \\
\hline BMI $\left(\mathrm{kg} / \mathrm{m}^{2}\right)$ & $0.985(0.961-1.010)$ & 0.239 & & \\
\hline Smoking status (Yes versus No) & $0.941(0.792-1.118)$ & 0.489 & & \\
\hline Drinking status (Yes versus No) & $1.001(0.812-1.234)$ & 0.993 & & \\
\hline FPG (mmol/L) (log-value) & $1.273(0.750-2.160)$ & 0.371 & & \\
\hline Albumin (g/L) & $1.002(0.989-1.015)$ & 0.767 & & \\
\hline Hemoglobin (g/dl) & $1.003(0.998-1.007)$ & 0.234 & & \\
\hline WBC $\left(\times 10^{9} / \mathrm{L}\right)$ & $0.995(0.996-1.026)$ & 0.756 & & \\
\hline Platelet count $\left(\times 10^{9} / \mathrm{L}\right)$ & $0.999(0.998-1.000)$ & 0.071 & $0.999(0.998-1.001)$ & 0.131 \\
\hline MPV (fL) $(\leq 10.0$ versus > 10.0) & $1.183(0.907-1.542)$ & 0.216 & & \\
\hline \multicolumn{5}{|l|}{ CA19-9 (IU/mL) } \\
\hline$(\leq 37$ versus $>37)$ & $1.843(1.488-2.284)$ & $<0.001$ & $1.757(1.408-2.193)$ & $<0.001$ \\
\hline \multicolumn{5}{|l|}{ Tumor location } \\
\hline (Head versus Body, tail) & $1.208(1.020-1.431)$ & 0.028 & $1.095(0.915-1.311)$ & 0.322 \\
\hline \multicolumn{5}{|l|}{ Tumor differentiation } \\
\hline (Poor versus Well/ moderate) & $1.709(1.324-2.206)$ & $<0.001$ & $1.809(1.400-2.337)$ & $<0.001$ \\
\hline \multicolumn{5}{|l|}{ Tumor size (cm) } \\
\hline$(>4$ versus $\leq 4)$ & $1.302(1.051-1.613)$ & 0.016 & $1.229(0.992-1.523)$ & 0.059 \\
\hline \multicolumn{5}{|l|}{ Regional lymph node metastasis } \\
\hline (N1 + N2 versus $\mathrm{N0})$ & $1.285(1.060-1.559)$ & 0.011 & $1.239(1.021-1.504)$ & 0.030 \\
\hline Chemotherapy (Yes versus No) & $0.800(0.679-0.943)$ & 0.008 & $0.774(0.654-0.916)$ & 0.003 \\
\hline
\end{tabular}


Table 4 Univariate and multivariate analysis of overall survival in PDAC patients with T2DM

\begin{tabular}{|c|c|c|c|c|}
\hline \multirow[t]{2}{*}{ Variables } & \multicolumn{2}{|l|}{ Univariate analysis } & \multicolumn{2}{|l|}{ Multivariate analysis } \\
\hline & HR $(95 \% \mathrm{Cl})$ & $P$-value & $\mathrm{HR}(95 \% \mathrm{Cl})$ & $P$-value \\
\hline Age (years) (> 60 versus $\leq 60)$ & $1.099(0.826-1.462)$ & 0.519 & & \\
\hline Gender (Male versus Female) & $1.289(0.963-1.725)$ & 0.087 & $1.083(0.795-1.476)$ & 0.614 \\
\hline $\mathrm{BMI}\left(\mathrm{kg} / \mathrm{m}^{2}\right)$ & $0.973(0.927-1.022)$ & 0.278 & & \\
\hline Smoking status (Yes versus No) & $1.052(0.770-1.436)$ & 0.750 & & \\
\hline Drinking status (Yes versus No) & $1.076(0.766-1.513)$ & 0.672 & & \\
\hline FPG (mmol/L) (log-value) & $1.165(0.792-1.713)$ & 0.439 & & \\
\hline Albumin (g/L) & $1.013(0.989-1.037)$ & 0.283 & & \\
\hline Hemoglobin (g/dl) & $0.998(0.989-1.008)$ & 0.706 & & \\
\hline WBC $\left(\times 10^{9} / \mathrm{L}\right)$ & $1.053(1.002-1.106)$ & 0.043 & $1.032(0.979-1.087)$ & 0.241 \\
\hline Platelet count $\left(\times 10^{9} / \mathrm{L}\right)$ & $1.000(0.999-1.002)$ & 0.629 & & \\
\hline MPV (fL) $(\leq 10.0$ versus > 10.0) & $1.914(1.414-2.592)$ & $<0.001$ & $1.801(1.305-2.485)$ & $<0.001$ \\
\hline \multicolumn{5}{|l|}{ CA19-9 (IU/mL) } \\
\hline$(\leq 37$ versus $>37)$ & $1.205(0.903-1.609)$ & 0.205 & $1.856(1.122-3.070)$ & 0.016 \\
\hline \multicolumn{5}{|l|}{ Tumor location } \\
\hline (Head versus Body, tail) & $1.053(0.779-1.424)$ & 0.736 & & \\
\hline \multicolumn{5}{|l|}{ Tumor differentiation } \\
\hline (Poor versus Well/ moderate) & $2.014(1.473-2.753)$ & $<0.001$ & $1.180(0.673-2.070)$ & 0.563 \\
\hline \multicolumn{5}{|l|}{ Tumor size (cm) } \\
\hline$(>4$ versus $\leq 4)$ & $1.460(1.091-1.955)$ & 0.011 & $1.385(0.832-2.303)$ & 0.210 \\
\hline \multicolumn{5}{|l|}{ Regional lymph node metastasis } \\
\hline (N1 + N2 versus N0) & $1.481(1.105-1.983)$ & 0.009 & $1.268(0.944-1.704)$ & 0.115 \\
\hline Chemotherapy (Yes versus No) & $0.166(0.119-0.232)$ & $<0.001$ & $0.183(0.128-0.261)$ & $<0.001$ \\
\hline
\end{tabular}

Abbreviations: see to Table 1

glycation end products (AGEs)-receptor interactions promote cell proliferation through the overexpression of platelet-derived growth factor-B [28]. These studies provided some biologic evidence for the roles played by activated platelets.

Our results are consistent with the studies above and indirectly confirmed the key role played by platelet activation. Moreover, these findings are also in accordance with the current idea that anti-platelet therapy is considered to be a part of adjuvant treatment of cancer [5]. A recent study confirmed that aspirin lessens the ability of platelets and inhibits PADC cell proliferation [29].

The underlying mechanisms of MPV involved in PDAC are unclear. Chronic inflammation plays a crucial role in the development and progression of PADC. MPV indicates platelets activation and low MPV levels reflect enhanced consumption of larger platelets in inflammatory states [12]. Previous studies confirmed that low MPV levels are linked with high-grade inflammatory diseases and reverse after anti-inflammatory treatment [12]. A recent study demonstrated that activated platelets released ADP and ATP and promoted pancreatic cancer cell survival via increasing cytidine deaminase expression [30]. In addition, tumor-infiltrating platelets predict a poor surgical outcome in PDAC patients [31].

Our results revealed the potential clinical significance of evaluating PADC prognosis using activated platelets. A report found that thrombocytosis and C-reactive protein influenced pancreatic cancer patient prognosis [32]. A meta-analysis showed that increased preoperative platelet to lymphocyte ratio had an association with reduced OS in PDAC [33].

Our study has certain limitations. First, our study was a retrospective and single-center design study with small sample size. In addition, the optimal cut-off value of MPV for OS prediction of $10.0 \mathrm{fL}$ at a sensitivity and specificity of 75.1 and $71.4 \%$ respectively requires independent validation. Second, the intrinsic mechanisms of MPV in PDAC need further investigation. Third, diabetes and pre-diabetes are frequently undiagnosed in PDAC patients. When tested for diabetes, the percentage of PDAC patients with DM is around $50 \%$. This increases if pre-diabetes is also considered. Therefore the incidence of diabetes reported in this cohort is likely to be underestimated. 


\section{Conclusions}

MPV independently predicts poor survival in PDAC patients with T2DM. Prospective studies are required to confirm the role of MPV in PDAC.

\section{Abbreviations}

IGF: Insulin-like growth factor; MPV: Mean platelet volume; PDAC: Pancreatic ductal adenocarcinoma; T2DM: Type 2 diabetes mellitus; WBC: White blood cells

\section{Acknowledgements}

Not Applicable.

\section{Authors' contributions}

JB $Y$ and RT $W$ conceived the study; JB $Y, N$ L, and RT $W$ participated in the design; JB Y, N L, MM C, and X W collected the data; and JB Y, N L, MM C, and $X W$ performed statistical analyses; JB $Y$ and $N L$ drafted the manuscript; $J B Y, N L$, and RT W edited and checked the manuscript. All authors have read and approved the final manuscript.

\section{Funding}

This work was supported from Nn10 program of Harbin Medical University Cancer Hospital. The funding body was not involved in the design of the study and collection, analysis, and interpretation of data and in writing the manuscript.

\section{Availability of data and materials}

The data in this study available from the corresponding author on reasonable request.

\section{Ethics approval and consent to participate}

The protocol was approved by the ethical committee review board of Harbin Medical University Cancer Hospital. All patients involved in the study gave written consent for this study.

\section{Consent for publication}

Not Applicable.

\section{Competing interests}

None of the authors have any competing interests.

Received: 9 December 2019 Accepted: 18 March 2020

Published online: 11 May 2020

\section{References}

1. Malvezzi M, Bertuccio P, Levi F, La Vecchia C, Negri E. European cancer mortality predictions for the year 2014. Ann Oncol. 2014;25(8):1650-6.

2. Chiaravalli M, Reni M, O'Reilly EM. Pancreatic ductal adenocarcinoma: stateof-the-art 2017 and new therapeutic strategies. Cancer Treat Rev. 2017;60: 32-43.

3. Rahn S, Zimmermann V, Viol F, et al. Diabetes as risk factor for pancreatic cancer: hyperglycemia promotes epithelial-mesenchymal-transition and stem cell properties in pancreatic ductal epithelial cells. Cancer Lett. 2018; 415:129-50

4. Mao Y, Tao M, Jia X, et al. Effect of diabetes mellitus on survival in patients with pancreatic Cancer: a systematic review and meta-analysis [J]. Sci Rep. 2015:5:17102. https://doi.org/10.1038/srep17102.

5. Mezouar S, Frere C, Darbousset R, et al. Role of platelets in cancer and cancer-associated thrombosis: experimental and clinical evidences. Thromb Res. 2016;139:65-76

6. Suzuki K, Aiura K, Kitagou M, et al. Platelets counts closely correlate with the disease-free survival interval of pancreatic cancer patients. Hepatogastroenterology. 2004;51(57):847-53.

7. Long Y, Wang T, Gao Q, Zhou C. Prognostic significance of pretreatment elevated platelet count in patients with colorectal cancer: a meta-analysis. Oncotarget. 2016;7:81849.

8. Pietrzyk L, Plewa Z, Denisow-Pietrzyk M, Zebrowski R, Torres K. Diagnostic power of blood parameters as screening markers in gastric Cancer patients. Asian Pac J Cancer Prev. 2016;17(9):4433-7.
9. Ekici H, Malatyalioglu E, Kokcu A, Kurtoglu E, Tosun M, Celik H. Do leukocyte and platelet counts have benefit for \preoperative evaluation of endometrial Cancer. Asian Pac J Cancer Prev. 2015;16(13):5305-10.

10. Qiu J, Yu Y, Fu Y, Ye F, Xie X, Lu W. Preoperative plasma fibrinogen, platelet count and prognosis in epithelial ovarian cancer. J Obstet Gynaecol Res. 2012;38(4):651-7.

11. Seretis $\mathrm{C}$, Youssef $\mathrm{H}$, Chapman M. Hypercoagulation in colorectal cancer: what can platelet indices tell us. Platelets. 2015:26(2):114-8.

12. Gasparyan AY, Ayvazyan L, Mikhailidis DP, et al. Mean platelet volume: a link between thrombosis and inflammation?[J]. Curr Pharm Des. 2011;17(1):47-58.

13. Huong PT, Nguyen LT, Nguyen XB, Lee SK, Bach DH. The Role of Platelets in the Tumor-Microenvironment and the Drug Resistance of Cancer Cells. Cancers (Basel). 2019:11(2):240.

14. Kemal Y, Demirağ G, Ekiz K, et al. Mean platelet volume could be a useful biomarker for monitoring epithelial ovarian cancer [J]. J Obstet Gynaecol. 2014;34(6):515-8. https://doi.org/10.3109/01443615.2014.912620.

15. Kumagai $\mathrm{S}$, Tokuno J, Ueda $Y$, et al. Prognostic significance of preoperative mean platelet volume in resected non-small-cell lung cancer [J]. Mol Clin Oncol. 2015;3(1):197-201. https://doi.org/10.3892/mco.2014.436.

16. Shen XM, Xia YY, Lian $L$, et al. Mean platelet volume provides beneficial diagnostic and prognostic information for patients with resectable gastric cancer [J]. Oncol Lett. 2016;12(4):2501-6. https://doi.org/10.3892/ol.2016.4913.

17. Tanriverdi $\mathrm{O}$, Menekse $\mathrm{S}$, Teker $\mathrm{F}$, et al. The mean platelet volume may predict the development of isolated bone metastases in patients with breast cancer: a retrospective study of the young researchers Committee of the Turkish Oncology Group (TOG)[J]. J BUON. 2016;21(4):840-50.

18. Li JY, Li Y, Jiang $Z$, et al. Elevated mean platelet volume is associated with presence of colon cancer [J]. Asian Pac J Cancer Prev. 2014;15(23): 10501-4.

19. Tetikoğlu M, Aktas S, Sagdık HM, Tasdemir YS, Özcura F. Mean Platelet Volume is Associated with Diabetic Macular Edema in Patients with Type-2 Diabetes Mellitus. Semin Ophthalmol. 2017:32(5):651-4.

20. Abalı G, Akpınar O, Söylemez N. Correlation of the coronary severity scores and mean platelet volume in diabetes mellitus. Adv Ther. 2014:31(1):140-8.

21. Turgut O, Zorlu A, Kilicli F, Cinar Z, Yucel H, Tandogan I, Dokmetas HS. Atrial fibrillation is associated with increased mean platelet volume in patients with type 2 diabetes mellitus. Platelets. 2013;24(6):493-7.

22. Han JY, Choi DH, Choi SW, Kim BB, Ki YJ, Chung JW, Koh YY, Chang KS, Hong SP. Stroke or coronary artery disease prediction from mean platelet volume in patients with type 2 diabetes mellitus. Platelets. 2013;24(5):401-6

23. Ünübol M, Ayhan M, Güney $\mathrm{E}$. The relationship between mean platelet volume with microalbuminuria and glycemic control in patients with type II diabetes mellitus. Platelets. 2012;23(6):475-80.

24. Huxley R, Ansary-Moghaddam A, de González AB, et al. Type-Il diabetes and pancreatic cancer: a meta-analysis of 36 studies [J]. Br J Cancer. 2005;92(11): 2076-83. https://doi.org/10.1038/sj.bjc.6602619.

25. Powell DR, Suwanichkul A, Cubbage ML, et al. Insulin inhibits transcription of the human gene for insulin-like growth factor-binding protein-1[J]. J Biol Chem. 1991;266(28):18868-76.

26. Pollak MN, Schernhammer ES, Hankinson SE. Insulin-like growth factors and neoplasia [J]. Nat Rev Cancer. 2004;4(7):505-18. https://doi.org/10.1038/nrc1387.

27. Ma J, Sawai H, Matsuo $Y$, et al. IGF-1 mediates PTEN suppression and enhances cell invasion and proliferation via activation of the IGF-1/PI3K/Akt signaling pathway in pancreatic cancer cells [J]. J Surg Res. 2010;160(1):90101. https://doi.org/10.1016/j.jss.2008.08.016.

28. Yamamoto Y, Yamagishi S, Hsu CC, et al. Advanced glycation endproductsreceptor interactions stimulate the growth of human pancreatic cancer cells through the induction of platelet-derived growth factor-B [J]. Biochem Biophys Res Commun. 1996;222(3):700-5.

29. Mitrugno A, Sylman JL, Ngo AT, Pang J, Sears RC, Williams CD, McCarty OJ. Aspirin therapy reduces the ability of platelets to promote colon and pancreatic cancer cell proliferation: Implications for the oncoprotein C-MYC. Am J Physiol Cell Physiol. 2017;312:C176-176C189.

30. Elaskalani O, Falasca M, Moran N, Berndt MC, Metharom P. The role of platelet-derived ADP and ATP in promoting pancreatic Cancer cell survival and gemcitabine resistance. Cancers (Basel). 2017;9(10):142

31. Zhang SR, Yao L, Wang WQ, Xu JZ, Xu HX, Jin W, Gao HL, Wu CT, Qi ZH, Li H, Li S, Ni QX, Yu XJ, Fu DL, Liu L. Tumor-Infiltrating Platelets Predic Postsurgical Survival in Patients with Pancreatic Ductal Adenocarcinoma. Ann. Surg. Oncol. 2018;25(13):3984-93. 
32. Miyamoto R, Oda T, Hashimoto S, Kurokawa T, Kohno K, Akashi Y, Ohara Y, Yamada K, Enomoto T, Ohkohchi N. Platelet $\times$ CRP multiplier value as an Indicator of poor prognosis in patients with Resectable pancreatic Cancer. Pancreas. 2017:46:35-41.

33. Song W, Tian C, Wang K, Zhang RJ, Zou SB. Preoperative platelet lymphocyte ratio as independent predictors of prognosis in pancreatic cancer: a systematic review and meta-analysis. PLoS One. 2017;12:e0178762.

\section{Publisher's Note}

Springer Nature remains neutral with regard to jurisdictional claims in published maps and institutional affiliations.

Ready to submit your research? Choose BMC and benefit from:

- fast, convenient online submission

- thorough peer review by experienced researchers in your field

- rapid publication on acceptance

- support for research data, including large and complex data types

- gold Open Access which fosters wider collaboration and increased citations

- maximum visibility for your research: over $100 \mathrm{M}$ website views per year

At $B M C$, research is always in progress.

Learn more biomedcentral.com/submissions 